\title{
Measles, mumps, and rubella: the need for a change in immunisation policy
}

\author{
DREW WALKER, HARDEN CARTER, IAN G JONES
}

\begin{abstract}
There is growing evidence that the present policy of childhood immunisation in the United Kingdom is inadequate. It is unlikely ever to achieve complete eradication of the congenital rubella syndrome and measles, and the problem of mumps has not even begun to be addressed. After a coordinated campaign to increase uptake of immunisation in Fife the uptake of rubella immunisation in teenage girls increased from $75 \%$ in 1981 to $94 \%$ in 1985 and the uptake of measles vaccination in preschool children from $55 \%$ in 1981 to $81 \%$ in 1985 . There are a few girls each year who do not accept rubella immunisation, whose immune state is unknown, and who are consequently at risk of rubella during future pregnancies. Despite the increased uptake of measles vaccine over the past four years there is currently an epidemic of measles in Fife, with 544 notified cases in the first quarter of 1986. In 1984, 19 Fife residents were admitted to hospital because of complications of mumps.
\end{abstract}

The time is ripe for a complete reassessment of the national immunisation policy.

\section{Introduction}

The current policy of immunisation in the United Kingdom is to offer protection against rubella only to schoolgirls and women of

\footnotetext{
Department of Community Medicine, Fife Health Board, Glenrothes, Fif KY7 5PB

DREW WALKER, MB, MSC, senior registrar

HARDEN CARTER, MRCP, MRCGP, specialist in community medicine

IAN G JONES, MD, MRCP, specialist in community medicine

Correspondence to: Dr Walker.
}

childbearing age who are not immune, to offer measles vaccine in the second year of life to all children, and not to vaccinate routinely against mumps. The elimination of the congenital rubella syndrome, measles, and mumps requires sufficiently high uptake of vaccine to achieve herd immunity. 'In 1981 only $75 \%$ of first year secondary schoolgirls in Fife were immunised in our annual rubella campaign and only $55 \%$ of children born in 1979 were protected against measles. No data are available on the susceptibility of our community to mumps. In response to this unacceptable state of affairs we set about reviewing our immunisation programme.

\section{Methods and results}

Rubella-We approached the problem of inadequate uptake of rubella vaccination by working with the local education authority to ensure a coordinated approach in schools. Staff arranged for all first year secondary schoolgirls to view a health education film on rubella and to take part in a discussion afterwards. Consent forms were then issued and checked against class lists. Two to three weeks later the vaccine was given and the record of immunisation completed. We persisted in tracing girls who had not been immunised, whom we had identified by name, until we were convinced that further follow up would be totally unproductive. Table I shows the initial results of the campaigns in 1984 and 1985 . Before the follow up of named girls $94 \%$ had been immunised in both years. After follow up $2583(97 \%)$ of the 1984 cohort and $2304(96 \%)$ of the 1985 cohort had been immunised or were naturally immune.

Measles-We have already reported on the improvements achieved in our measles immunisation programme. ${ }^{2}$ In $1981,55 \%$ of children born in 1979 were immunised. Our most recent survey of 297 children born in December 1983 indicated that $241(81 \%)$ were vaccinated before their second birthday. For all preschool children the uptake of immunisation is currently over $80 \%$. Table II shows that, despite this improvement, this uptake is still inadequate in preventing epidemics. Whereas 236 cases of measles were notified in Fife during the whole of 1985,544 cases were reported during the first quarter of 1986. Of this year's cases, 33 were infants, 128 other preschool children, 332 schoolchildren aged 5-15, and 51 aged 16 or over. A total of 95 had been 
TABLE I-Results of initial rubella campaigns among first year secondary schoolgirls in Fife, 1984-85

\begin{tabular}{|c|c|c|}
\hline & \multicolumn{2}{|c|}{ No (\%) of schoolgirls } \\
\hline & 1984 & 1985 \\
\hline \multirow{2}{*}{$\begin{array}{l}\text { Immunised by clinical medical officer } \\
\text { Immunised by general practitioner } \\
\text { or other doctor }\end{array}$} & $2155(81)$ & $1853(77)$ \\
\hline & $339(13)$ & $393(16)$ \\
\hline Still to attend general practitioner & 13 & $39 \quad(2)$ \\
\hline Immunisation refused & (2) & $55 \quad(2)$ \\
\hline Absent & (3) & $57 \quad(2)$ \\
\hline Unaccounted for & 32 (1) & \\
\hline Total & $2662(100)$ & $2397(100)$ \\
\hline
\end{tabular}

TABLE II-Notification of measles in Fife, 1985-6

\begin{tabular}{cccccc}
\hline & \multicolumn{4}{c}{1985} & 1986 \\
\cline { 2 - 5 } & Jan-Mar & April-June & July-Sept & Oct-Dec & Jan-Mar \\
\hline Notifications & 18 & 43 & 92 & 83 & 544 \\
\hline
\end{tabular}

immunised; included among these were 87 of the 451 children aged 2-15, all of whom came within the age group that should have been protected.

Mumps-We reviewed the hospital case notes for residents in Fife admitted with mumps in 1984, a year in which laboratory reports for Scotland as a whole suggested a low incidence of the disease. ${ }^{3}$ Whereas only six patients with measles needed admission in that year, 19 required admission for mumps. Complications included aseptic meningitis (11 patients), mild pancreatitis (two), febrile convulsions (two), arthritis (one), and orchitis (one). All patients were over 18 months of age, and the average duration of stay in hospital was 6.6 days; three patients required admissions of two weeks or more.

\section{Discussion}

Clearly, high uptake of rubella immunisation can be achieved if inertia in the health service is replaced by a coordinated strategy; such a strategy increased uptake in our area from $75 \%$ to $94 \%$. We have now reached the stage of dealing with named schoolgirls who have escaped the net, and each is followed up individually. This approach, however, has increased the total vaccinated by only a further $2-3 \%$, and several problems remain. Firstly, several girls still refuse immunisation for various reasons. Secondly, we do not know which girls fail to acquire protection by immunisation. Thirdly, there is always uncertainty about the immune state of those who are educated outside the state system or who attend schools outside our areas.

A much more serious criticism of the present arrangements in the United Kingdom is that they have failed to prevent the cyclical pattern of rubella. ${ }^{4}$ In contrast, the United States, with its policy of universal childhood rubella immunisation, has since 1977 consistently reported fewer annual registrations of the congenital rubella syndrome than the United Kingdom. In 1983, the most recent year for which complete figures are available, 25 cases of the congenital rubella syndrome were registered in the United Kingdom but only seven in the United States, a country with four times our population. In 1984 only two cases were registered in the United States. ${ }^{5}$ We are aware that the figures for the United States probably underestimate the true incidence of the congenital rubella syndrome for several reasons, but these factors are equally applicable to the reporting system in the United Kingdom. ${ }^{5}$

We agree with those who have recently voiced dissatisfaction with the current unscientific policy in the United Kingdom and believe that the time has come to change this strategy to a programme of universal immunisation..$^{6-8}$ We propose that the aim should be the eradication of rubella from society, and this will ultimately require the immunisation of all children.
There is an excellent case for combining measles, mumps, and rubella immunisation at 15-18 months of age as is currently done in the United States and several other countries. By adopting such $\frac{\mathrm{a}}{\mathrm{a}}$ policy in 1982 Sweden has shown that the complete eradication of measles, mumps, and rubella is entirely practicable. ${ }^{910}$ More recently Finland has considerably reduced the incidence of these three diseases in its vaccinated population. ${ }^{1}$ Model prediction suggest that a multistage policy that achieved $60 \%$ immunisation of 2 year old children, plus a continuation of the current policy in the United Kingdom of vaccinating teenage girls and continued surveif lance and vaccination of adult women of childbearing age, woula reduce the incidence of the congenital rubella syndrome ${ }^{11}$; succes in eradicating the rubella virus is crucially dependent on the uptake of vaccine, and uniform vaccination of more than $80-85 \%$ of young children could achieve this. ${ }^{12}$ We believe that a single vaccine the protects children against measles, mumps, and rubella rather that against measles alone will be more attractive to parents, thus furth boosting its uptake. Donaghy argued that the epidemiological shigf of mumps towards older age groups that occurs with a one dose programme still produced a net reduction in the number of cases and complications. ${ }^{3} \mathrm{~A}$ two dose policy, however, would minimise such a shift ${ }^{13}$ and could, for example, virtually eliminate the congenital rubella syndrome in 10 years. We should therefore follo the Finnish and Swedish example of reimmunising children at the age of 6 or 12. ${ }^{110}$ Uptake of measles immunisation in Fife has rises dramatically in recent years but, disappointingly, is not yet higd enough to have prevented our current epidemic. Much wor\& remains to be done if we are to achieve the aims of the second conference on immunisation policies in Europe, which included the elimination of measles by 1990 and congenital rubella by 2000. Although the incidence of mumps may be decreasing in Scotland음 the disease is clearly still responsible for several unnecessary admissions to hospital with unpleasant and undesirable complice tions.

The administrative difficulties of adopting the Scandinaviant model are less than might be expected. Measles-mumps-rubelig vaccination at 15-18 months of age can be substituted for measles vaccine alone, and giving multiple vaccination at 12 years of age to both boys and girls means that the only extra work is immunisin boys, as girls are already being immunised. Vaccination of wome of childbearing age who are not immune would of course continue at present. The effectiveness of such an immunisation schedule ha\& we believe, been proved, and this provides a basis for a decision $\vec{\theta}$ change the policy in the United Kingdom. Until we adopt this approach and fall into line with Scandinavian practice there is prospect of rubella, measles, or mumps ever being eradicated in this country. The time to start doing this is now.

\section{References}

1 Peltola $\mathrm{H}$, Karanko, $\mathrm{V}$, Kurki $\mathrm{T}$, et al. Rapid effect on endemic measles, mumps, and rubella nationwide vaccination programme in Finland. Lancet 1986;i:137-9.

2 Carter H, Jones IG. Measles immunisation: results of a local programme to increase vaccing uptake. Br Med J 1985;290:1717-9.

3 Donaghy M. Epidemiology of mumps in Scotland. Communicable Diseases Scotland Unit Wee Repon 1984;42:xi-xvii.

4 Smithells RW, Sheppard S, Holzel H, Dickson A National congenital rubella surveillan programme 1 July 1971-30 June 1984. BrMed f 1985;291:40-1. programme 1 July 1971-30 June 1984. BrMed $1985 ; 291: 40-1$.
Communicable Diseases Centre. Rubella and congenital rubella syndrome-United Stat Communicable Diseases Centre. Rubell

6 Brook CGD. Immunisation policies. Br Med f 1983;286: 1082-3.

7 Miller CL, Miller E. Rubella vaccination in the UK: time for a complete strategy. Lantegt $1985 ; \mathrm{ii}: 732$.

8 Miller CL, Miller E, Sequeira PJL, et al. Effect of selective vaccination on rubella susceptibil and infection in pregnancy. BrMed $\mathcal{F}$ 1985;291: 1398-401

9 Taranger $\mathrm{J}$. Vaccination programme for eradication of measles, mumps and rubella. Lancet 1982;i:915-6.

10 Christenson B, Bottiger M, Heller $L$. Mass vaccination programme aimed at eradicating measie mumps, and rubella in Sweden: first experience. $B r$ Med $\mathcal{J}$ 1983;287:389-91.

11 Anderson RM, Grenfell BT. Control of congenital rubella syndrome by mass vaccination. Lan 1985;ii:827-8.

12 Anderson RM, Grenfell BT. Quantitative investigations of different vaccination policies for the control of congenital rubella syndrome (CRS) in the United Kingdom. $\mathcal{f}$ Hyg (Can 1986;96:305-33.

13 Rabo E, Taranger J. Scandinavian model for eliminating measles, mumps, and rubella. $\mathrm{Br} M e{ }_{0}$ 1984;289:1402-4. 